\title{
Music therapy microanalysis of parent-infant interaction in a three-month-old infant later diagnosed with autism
}

\begin{abstract}
BACKGROUND
Infant research literature has described for a long time the main aspects of parentese (motherese and fatherese) referring to musicality and specifically to musical language. It is believed that there is a deep analogy between the vital affects experienced by the child during interaction with the parent and the type of parentese that is a direct representation of them. Disruption of parentese has been described in early autism. The aim of this paper was to achieve a better understanding of this disruptive process.
\end{abstract}

\section{PARTICIPANTS AND PROCEDURE}

Sequences of parent-infant interaction extracted from one home movie of a child later diagnosed with autism were analyzed in a micro-musical way in order to create a musical score that allows the description of parent-infant interaction in a new way (considering form, pulse, rhythm, melody, timbre and silence).

\section{RESULTS}

Musical microanalysis is able to highlight features not brought out by other kinds of analysis. The first fragment is dominated by the anxiety of the mother, who attempts to stimulate the unresponsive infant. In the second fragment there is a change in musicality parallel to changes in the relationship: the mother participates in and coordinates the infant's experience through rhythm, prosody and musical dynamics. This change persists in the third fragment.

\section{CONCLUSIONS}

Musical transcription of parent-infant interactions has allowed us to highlight changes occurring in a short time during early interactions and to get a closer view of the disruptive process created by autism. This kind of research represents a potential shift in autism research, by focusing on dynamic parent-infant interactions instead of single behaviors of the child or of the parent. The usefulness of Stern's concept of intersubjective communion is discussed.

KEY WORDS

autism; infant; music; microanalysis 
To see a World in a Grain of Sand

And a Heaven in a Wild Flower, Hold Infinity in the palm of your hand

And Eternity in an hour.

W. Blake (1803)

\section{BACKGROUND}

Ferdinando

Michele Suvini,

Fabio Apicella,

Filippo Muratori

Autism spectrum disorders (ASDs) are neurodevelopmental disorders characterized by difficulties in social interaction and communication, and by a restricted, stereotyped and repetitive repertoire of interests and activities (WHO, 1992; APA, 2013). The full-blown picture of many ASDs only becomes evident during the second year of life, but the underlying neurobiological autistic process begins long before. Retrospective studies of home videos spontaneously recorded by parents during their child's infancy and before diagnosis offer a way to look at autism during this early period of life when behavioral symptoms are still not clearly evident. It has been suggested that these studies, which directly assess real-life, realtime reciprocal interactions, represent a potential paradigm shift in autism research (Schore, 2014).

\section{PARENT-INFANT INTERACTION IN THE HOME MOVIES OF INFANTS WITH AUTISM}

For a long time, our research using family movies (Saint-Georges et al., 2010) was focused on infant's attentional skills, describing a pattern characterized by an early lower social attention (Maestro et al., 2002) and by an atypical longitudinal increase of non-social attention during the first year of life (Maestro et al., 2004). Autism spectrum disorders infants do not show the increasing social engagement that characterizes infants with typical development (TD) and, in particular, the typical propensity of infants to seek interactive experiences and sympathize with the intentions and feelings of others.

Only more recently have early interactions between parents and infants been analyzed. This new research has enabled us to highlight, in the same videos, an early interactive style, capable of differentiating dyads which include infants who will develop an ASD from dyads with infants who demonstrate TD or cognitive delay. This interactive style is characterized by a reduction of inter-subjective skills in the infant (that is a lowering of syntony, of acceptance of others' invitations, of maintenance of social engagement, of orienting to their name) and by a parallel increase of parents' behaviors aimed at engaging their infant in interaction through an increase of touch, voice and movement. We have named this parental style 'up regulation' to differentiate it from those parental behaviors characterized by acts designed to calm the child and reducing the amount of tactile, auditory and motor stimulation (Muratori, Apicella, Muratori, \& Maestro, 2011). This latter kind of dyadic behavior is, on the contrary, rare in parents of infants who are developing autism. The 'up regulation' behaviors are infrequent when parents respond to the interactive initiative of their infant, but they increase when it is the parent who initiates the interaction. This decrease in 'up regulation' behaviors when the child drives the interaction has led us to think that this style is not 'endogenous', but strictly dependent on the partner's interaction. We have found that this interactive style is already prevalent in the first six months of life of infants with ASD, when the parents still have no conscious awareness of the disorder that affects their child. Through 'up regulation' caregivers seem to be 'aware' of the low intersubjective engagement of their infant and we could think that by using this interactive style parents are able not only to recognize, in an implicit way, their infant's deficiency in inter-subjective initiative, but also to compensate it by increasing the quantity of solicitations towards their child (Saint-Georges et al., 2011). We have also hypothesized that the 'up regulation' style of parent-infant interaction may become an indicator for the early identification of ASD. More recently, we have observed how this interactive style is part of a more general deficiency in interactive reciprocity characterized by reduced motor activity, fewer vocalizations, asynchronous vocal-motor patterns in the child, and less involvement and less use of 'affectionate touch' in the parents (Apicella et al., 2013). Our results are in line with other recent studies on siblings of children already diagnosed (Wan et al., 2012), and could have important repercussions regarding the role that has been attributed to parent-mediated treatments, which are aimed at enhancing supportive interactions in everyday life (Oono, Honey, \& McConachie, 2013).

Subsequently, we have found that 'up regulation' is full of motherese, and that this specific prosody appears to stimulate the infant's responses as a whole, and in particular the infant's responses towards people. We have hypothesized that it could represent an augmentative parental behavior which may obscure atypical social attention in affected infants. Because fathers can also talk in motherese (O'Neill, Trainor, $\&$ Trehub, 2001), from now on we use the term parentese instead of motherese or fatherese.

\section{PARENT-INFANT RELATIONSHIP: THE THEORETICAL FRAMEWORK}

When parents interact with their baby, no particular didactic aim is in their mind: the parent is not planning to teach the child a specific skill, or pursue a certain line of conversation. Parent-infant interac- 
tion takes place on pre-verbal and pre-linguistic levels, where it is not words that count, but instead what lies underneath, or what the word's sound itself is trying to convey. Second, the interaction takes place on a level of shared affects: the primary parent-infant relationship is at the same time the object and the objective of the interaction. Third, the interaction allows for the co-construction of shared meanings within the dyad: the parent is not intending to teach anything, yet the child is still learning (Giusti \& Suvini, 2014).

The confluence of these different inner times, of the caregiver and of the infant, could create an intersubjective inner time described as "common reality" (Gratier, 2009), that is fundamental for the development of primary inter-subjectivity (Trevarthen \& Aitken, 2001). The theoretical frame of inter-subjectivity, that is supposed to be lacking in autism (Muratori \& Maestro, 2007), considers different units. First, there is reciprocity that can be defined as an interactive condition in which two individuals mutually respond to each other while performing activities together (Apicella et al., 2013; Cohen et al., 2013). Another unit to be analyzed is called 'vitality affects', which are inter-events that do not belong to the individual but are generated inside a relational process (Stern, 2010a, 2010b). A third aspect of intersubjectivity concerns sound and music, as an implicit form of speech based on the assumption that it has a psychological reality even before its symbolic meaning. From this perspective, the implicit knowledge begins to be represented in a pre-verbal form that is already present in the early stages of development and that occurs throughout the course of life in a continuous interaction of preverbal and verbal modes of communication. All these units are linked to the fundamental difference between interpersonal communication and interpersonal communion. Interpersonal communication is based on the concept of sharing thoughts or information, with the deliberate aim of changing the behavior or thinking of other people. Interpersonal communion is based on the concept of participating in, and coordinating with, the other's experience (in rhythm, prosody and musical dynamics) without trying to change it but seeking only to share (Stern, 1985).

\section{PARENTESE, MUSIC AND MUSIC THERAPY}

For a long time, infant research literature has described the main aspects of parentese using terms which refer specifically to musicality and music of language (Fernald, 1985). It is believed that there is a clear analogy between the vital affects experienced by the child during interaction, and the music of parentese that is a direct representation of them (Stern, 1985). In fact, vital affects are usually described as 'crescendo', 'diminuendo', 'calando', and 'esplodendo', which define a specific change in music too. Parentese is a particular type of language used by adults, especially parents, when interacting with babies and very young children. Parentese has its own particular articulation, intonation, punctuation, pauses, repeated words, and cyclical variations of emotions and musical prosodic aspects: longer pauses, slower tempos, more repetitions, higher pitch, and exaggerated contours (Fernald, 1985; Saint-Georges et al., 2013). Lexical aspects are shorter utterances, simpler and redundant utterances, isolated words and phrases, a large number of questions, and frequent use of proper names (Durkin, Rutter, \& Tucker, 1982; Soderstrom, Blossom, Foygel, \& Morgan, 2008). Words and constructions derived from normal language often make use of the third person instead of the first or second one (Ferguson, 1964).

The specific prosodic and rhythmic features of parentese are able to involve children in social interaction, even when the children are extremely withdrawn and have little desire to interact with others. For this reason, parentese is also particularly powerful for activating interactive skills in autistic subjects (Muratori \& Maestro, 2007; Saint-Georges et al., 2013). Home videos have shown that parentese can play an important role in opposing the tendency to withdrawal in autistic babies (Muratori \& Maestro, 2007; Trevarthen \& Aitken, 2001). Moreover, different studies have shown that parentese is not only a language that adults use in a very specific way when communicating with a baby, but it is also a co-construction that develops within early proto-dialogues. When a child reacts positively to the parents, the prosodic peaks of their parentese increase (Burnham, Kitamura, \& Vollmer-Conna, 2002). Therefore, the typical hypo-responsiveness found in autism can potentially trigger a vicious circle in which the decrease of parentese has a negative impact on the whole parent-child relationship (Danon-Boileau, 2007). Hypo-responsiveness and lack of interpersonal involvement of infants with autism can alter the entire space where the dyadic interaction takes place (Garcia-Perez, Lee, \& Hobson, 2007).

All the elements that characterize parentese are drawn from forms of music in order to construct shared affects on a pre-verbal level. It was suggested that, through the use of a non-verbal channel, clinical improvisation could make it possible to co-construct a shared trajectory of interaction (Geretsegger et al., 2015), even in the face of strong or absolute hypo-responsiveness. Like in parentese, in music therapy interaction is constructed in a shared dual space. This is the key point: the parent, through parentese, like the therapist with musical sounds, never creates music alone because never she/he is alone in the relationship. Although autistic children may seem unresponsive to their parents, or do not play any instrument, the parent/therapist's music is always connected to
Microanalysis of early parent-infant interactions in autism 
some aspect of the experience or to the presence of the autistic child (Giusti \& Suvini, 2014).

\section{AIMS OF THE STUDY}

In accordance with these ideas, the present article aims to investigate, during early interactions, the importance of parent-infant reciprocity and synchronicity from a specific musical perspective. We refer to three short sequences of early mother-infant interactions, extracted from the home movie of a child later diagnosed with autism. Video sequences have been microanalyzed in a musical scenario in order to create a musical score. In turn, we expect to find a new way of describing mother-infant interactions.

The hypothesis is that musical transcriptions of interactions may make it possible to highlight, through a specific and detailed exploration of elements (such as form, pulse, rhythm, melody, timbre and silence), the main characteristics of reciprocity, inter-subjectivity and inter-personal communion in early development. Moreover, through this kind of musical analysis (Ansdell, Davidson, Magee, Meehan, \& Procter, 2011; Suvini, 2015), we hypothesize a better understanding of the process of early parent-infant interactions created and disrupted by autism during the first months of life. Finally, the objective of the musical microanalysis is to evaluate the quality of the relationship and of interpersonal skills, in addition to the fundamental dimensions of time, form and intensity as basic events through which the interpersonal coordination occurs (Stern, 2010b; Wigram \& Gold, 2006).

\section{PARTICIPANTS AND PROCEDURE}

Three episodes from a home movie of a three-monthold infant, later diagnosed with autism, were selected. In all the three episodes the mother-infant relationship was clearly visible; the first episode lasts 9 seconds; between the first and the second episode 30 seconds pass; the second episode lasts 12 seconds and is immediately followed by the third episode that lasts 10 seconds. The video was shot at home when the infant was three months old, immediately after he woke up in the cradle. The videos were selected from the Stella Maris Research Center - Pisa Home Movies database. This database was collected over the years thanks to parents who arrived at Stella Maris for diagnosis when their children were about four years old. Parents gave their consent to use their home movies for research. In adherence to the right and protection of privacy, all video material was treated as sensitive data. Its management and use was strictly in accordance with the law. All data were stored anonymously in a secure area, with access limited to just the music therapist (FS).
Initially the musical material was manually transcribed as a score. Afterwards the Musescore 2.0.3 program was used because it allows an accurate presentation of the material, although transcription with this program is extremely time-consuming when working at a high level of precision. The score uses traditional symbols from Western musical notation. This method is considered very sensitive for monitoring repetitive elements or minimum changes relative to form, duration, rhythm and intensity and all the parameters which are subjected to analysis (Wosch \& Wigram, 2007; De Backer, 2004). In accordance with the main intersubjective literature, the themes selected for analysis were: Narrative and Form; Pulsation and Rhythm; Repetition and Imitation; Intensity; Timbre; Pitch and Melody; Pause and Silence; Semantic or Verbal Meaning (see Table 1).

\section{RESULTS}

Tables 2, 3 and 4 show the results of the microanalysis of the three episodes. In these three episodes it is possible to see how musical microanalysis is able to highlight features and details of parent-infant interaction and how musical interactions that the mother offers to the 3-month-old infant influence and are influenced by the relationship with the child.

\section{FIRST EPISODE}

Mother's and infant's parameters are different in pulse, rhythm, intensity, and pitch. The mother does not adjust the pulse of her vocalizations or vary the quality (rhythm, pitch, intensity). There is only one fragment of partial imitation, but differences between mother and child in pulse, rhythm, pitch, intensity and timbre persist also in this fragment.

\section{SECOND EPISODE}

The second episode shows some evidence of a change in the quality of musical interaction. The mother shows more possibilities to participate and coordinate with the rhythm, pitch, intensity, timbre of the infant's experience. The mother proposes two similar musical phrases, separated by a short pause; the repetition of the phrase is full of melodic form ('ascendendo', 'discendendo'); at the end of the two phrases there is an affective attunement through reciprocal laughing.

\section{THIRD EPISODE}

The mother proposes a regular phrase and imitates the child's vocalizations. There is reciprocity in pitch, 
Table 1

Themes for the musical microanalysis

Themes for the musical microanalysis

In their "conversation" mother and infant share inner experience, make sense to each other and make meaning for each other. Mother and infant adjust the pulse of their vocalizations and systematically vary the quality of their expression to produce a nar-

Narrative rative lasting tens of seconds (Malloch, 1999), anticipating and regulating the cycle

\& Form of emotional intensity in what is called a "proto-narrative envelope" (Stern, 1985). Vitality affects are both "narrative of becoming" and "experience of now" (Stern, 2004, $2010 \mathrm{a}, 2010 \mathrm{~b})$. The realm of meaning which the infant accesses through temporal and qualitative coordination is rooted in, and develops from, present embodied experience (Gratier, 2009).

There is a dynamic and subtle equilibrium between known and new, between structure and variation, in order to generate an inner sense of time. Pulse, rhythm and repetition are directly connected with belonging and identity, creating an inner sense of the self. Pulse Change, variation, and novelty are directly connected with creativity, curiosity, and \& Rhythm imagination. It is interesting to note that an infant's capacity to parse stimuli in order to anticipate and predict events is present at a very early stage (Gratier, 2009). It is known that infants from 2 to 4 months prefer tempos of 60 beats per minute. This is called "the spontaneous tempo" (andante or moderato), and is connected with cycles of attention and kinesic activity (Brazelton, 1984).

Through imitation, mirroring, antiphony, turn-taking or synchronous play, the moth-

Repetition

\& Imitation er's musicality may include the infant's musicality in parameters such as rhythm, pitch, intensity and form. Mid-range coordination at 4 months can predict secure attachment at 12 months. High or low levels of vocal rhythm coordination predict insecure attachment.

Intensity

The intensity base line of intensity is the medium range, between $m p$ and $m f$. Pianissimo $(p p)$ and fortissimo (ff) mean a high intensity level as well.

Timbre plays a major role in the expression and perception of emotion in speech and song. Timbre is deeply connected with identity and sense of self. The mother's presence is differentiated from the infant's presence through timbre (Malloch, 1999; Trehub

Timbre \& Nakata, 2002). Timbre inhabits places in which words are missing, or rather where the words are rarely referred to the acoustic perception. It is very often directed towards other areas of perception: hot and cold, soft and hard, dry, bitter, sweet, pungent, shrill.

In primary inter-subjectivity, the infant needs more melodic stability than variability. Repetition with subtle variation provides anticipation and predictable material. Infants like very simple melodic songs, such as lullabies. They prefer music or songs that are slower in tempo and have fewer dynamic and melodic changes (Wigram \& Elefant, 2009).

Measuring parameters of "silence", "pause" and "switching pause" is important in order to demonstrate how adults slow and regulate the rhythm of speech when they talk to an infant. Infants need listening and silence, because they need time to organize

Pause \& Silence themselves to respond (Holck, 2004). Delays in response could be caused by difficulties in self-organization and by uncontrolled movement (Wigram \& Elefant, 2009). Mothers must make space in order to give their infants time to interject their own material (Bruscia, 1987).

Lexical aspects include shorter utterances, simpler and redundant utterances, isolated words and phrases, a large number of questions, and the frequent use of proper names Semantic or (Fisher \& Tokura, 1995; Grieser \& Kuhl, 1988; Durkin, Rutter, \& Tucker, 1982; SoderVerbal Meaning strom, Blossom, Foygel, \& Morgan, 2008).

Words and constructions are derived from normal language, such as the use of the third person instead of the first or second (Ferguson, 1964).
Microanalysis of early parent-infant interactions in autism 
Table 2

Musical transcription of episode 1 and its microanalytic description and evaluation

Ferdinando Michele Suvini, Fabio Apicella, Filippo Muratori

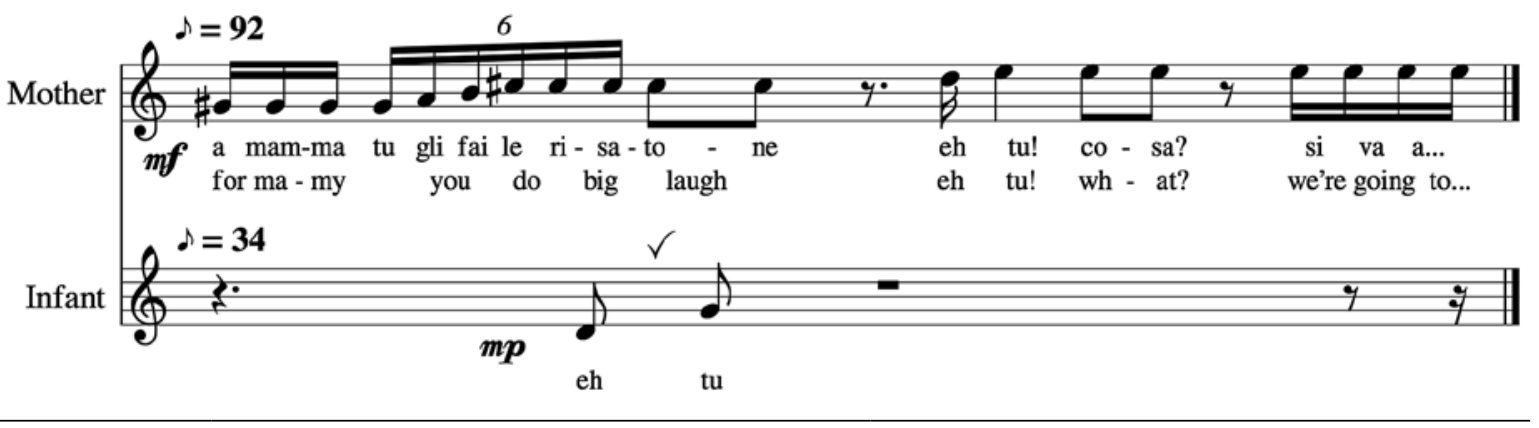

$$
\text { Description }
$$

$\begin{aligned} & \text { Narrative } \\ & \text { \& Form }\end{aligned}$
$\begin{gathered}\text { Musical material is mostly proposed by } \\ \text { mother ( } 9 \mathrm{~s} \text { vs. } 2 \mathrm{~s}) .\end{gathered}$
Pulse

The mother's material shows rhythm variRhythm ability. It is very fragmented, there are constant changes in rhythm, and the different proposals are not connected to each other.

Repetition

\& Imitation

No imitation or repetition is present.

Intensity

The mother's intensity is almost always mezzoforte $(m f)$, the infant's mezzopiano $(m p)$.

Shrill timbre from the mother and soft timbre from the infant.

Pitch

\& Melody

A very high range for the mother and a medium range for the infant.

Pause

\& Silence

No pause or silence.
Evaluation

The mother is trying to reach the infant but is not listening to him.

The mother's pulsation is much faster than the infant's.

The mother's musical material does not have regularity or predictability, and does not allow for dialogue or reciprocity.

The musical material is based on the mother's proposal, seldom including the infant's proposal.

The mother tries to reach the infant directly but is not able to regulate her intensity towards him.

Timbre represents the identity or the inner self, and here the mother's and infant's are very different.

There is a very wide pitch range.

There is no space for sharing or listening to the infant.

Semantic

Mother refers directly to the infant.

At the end of the phrase the mother refers to a future action.

intensity and timbre, although there is no reciprocity in form, rhythm or pulsation. The episode of imitation involves rhythm, intensity, pitch and timbre. Through this imitation, the mother's musicality includes the infant's musicality (rhythm, pitch, intensity and form). There is a dynamic equilibrium between structure and variation that generates an inner sense of time.

\section{DISCUSSION}

The aim of this paper was to investigate reciprocity and synchronicity in early parent-infant interactions, from a specific musical perspective. The hypothesis was that musical transcriptions of interactions, in terms of form, pulse, rhythm, melody, timbre and silence, could make it possible to highlight characteristics of the interactive style and its changes in a short period of time. To achieve this aim we have deeply analyzed video material from the home video of a threemonth-old infant later diagnosed as affected by ASD.

Previous studies on a larger number of home videos have already analyzed spontaneous parent-infant interactions in both ASD and TD infants from a behavioral point of view (Muratori et al., 2011; Apicella et al., 2013). In these studies ASD infants showed a reduction in the duration of spontaneous social behavior such as maintaining social engagement, enjoying being with people, propensity to seek interactive experiences and in sympathizing with the intentions of others. Then we have described how this 
Table 3

Musical transcription of episode 2 and its microanalytic description and evaluation

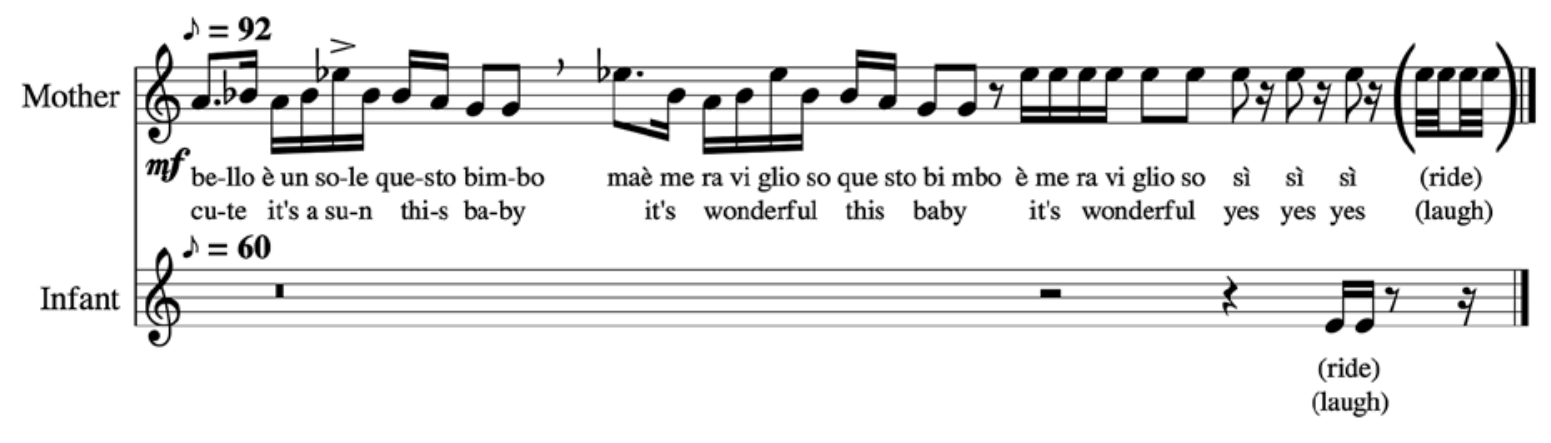

\begin{tabular}{|c|c|c|}
\hline & Description & Evaluation \\
\hline $\begin{array}{l}\text { Narrative } \\
\& \text { Form }\end{array}$ & $\begin{array}{c}\text { Musical material is mostly proposed by } \\
\text { the mother. }\end{array}$ & $\begin{array}{l}\text { The mother's music is more regular in } \\
\text { rhythm and melodic aspects. }\end{array}$ \\
\hline Pulse & $\begin{array}{l}\text { The mother's metronome beat is } 92, \\
\text { the infant's is } 60 .\end{array}$ & $\begin{array}{l}\text { The mother's pulsation is faster than that } \\
\text { of the infant. }\end{array}$ \\
\hline Rhythm & $\begin{array}{l}\text { The rhythm is more stable than before: } \\
\text { there is regularity and phrasing. }\end{array}$ & $\begin{array}{l}\text { The mother's musical material is predictable } \\
\text { and allows for reciprocity. }\end{array}$ \\
\hline $\begin{array}{l}\text { Repetition } \\
\text { \& Imitation }\end{array}$ & $\begin{array}{l}\text { The musical material is based on repetition } \\
\text { and imitation. }\end{array}$ & $\begin{array}{l}\text { The mother's repetition could be thought } \\
\text { of as expressing greater self-confidence. }\end{array}$ \\
\hline Intensity & $\begin{array}{l}\text { The mother's intensity is almost always mez- } \\
\text { zoforte }(m f) \text {, the infant's is mezzopiano }(\mathrm{mp}) \text {. }\end{array}$ & $\begin{array}{l}\text { The mother is often } \\
\text { stronger than the infant. }\end{array}$ \\
\hline Timbre & $\begin{array}{l}\text { Shrill timbre from the mother and soft tim- } \\
\text { bre from the infant. }\end{array}$ & $\begin{array}{l}\text { Timbre represents the identity or the inner } \\
\text { self, and the two timbres are very different. }\end{array}$ \\
\hline $\begin{array}{l}\text { Pitch } \\
\& \text { Melody }\end{array}$ & $\begin{array}{l}\text { A high range (but stable) from the mother } \\
\text { and a medium range from the infant. }\end{array}$ & $\begin{array}{l}\text { There is a wide pitch range and melodic } \\
\text { difference. }\end{array}$ \\
\hline $\begin{array}{l}\text { Pause } \\
\& \text { Silence }\end{array}$ & $\begin{array}{l}\text { No pause or silence, but the mother is more } \\
\text { connected with her emotions. }\end{array}$ & $\begin{array}{l}\text { There is more space for the infant in the } \\
\text { inner world of the mother. }\end{array}$ \\
\hline Semantic & \multicolumn{2}{|c|}{$\begin{array}{l}\text { The mother's language relates to the present moment (Stern, 2004), } \\
\text { in an interpersonal communion way. }\end{array}$} \\
\hline
\end{tabular}

Microanalysis of early parent-infant interactions in autism lack of infant inter-subjectivity shaped the early parent style of interaction: in response to a socially under-active ASD infant, parents assume that the infant needs to be more solicited, and adopt a hyper-stimulating style (Saint-Georges et al., 2011). This interactive hyperstimulating style, which we have called "up-regulation", was previously described by Doussard-Roosevelt, Joe, Bazhenova, and Porges (2003) and by Trevarthen and Daniel (2005), who reported that parents of ASD overstimulate their infants as a result of the infants' inactivity.

In this paper we have sought to broaden this behavioral research on home movies through a musical microanalysis of parent-infant interactions. Three short sequences, extracted from a home movie of a three-month-old child later diagnosed with ASD, have been microanalyzed in a musical way. In the first episode, vocalizations of the mother and of the infant were different for all parameters (pulse, rhythm, intensity and pitch). There is a lack of synchrony and syntony that persists also during a brief imitation. We could suggest that the musical asynchrony could be the expression of the mother's difficulties in approaching the withdrawn child. Musically, the mother shows difficulties in changing her rhythm so that she is very far from a propensity to coordinate musical dynamics of the infant's experience. It seems that the mother tries more to alter the experience of the infant than to build up a shared musical environment. In the second episode the mother proposes two similar phrases rich in musicality and separated by a short pause; at the end of the second phrase there is an affective attunement through laughing. We could hypothesize that the mother has now more possibilities to participate and coordinate with the rhythm, pitch, intensity, and form of the infant's experience. According to previous studies (Muratori \& Maestro, 2007), the mother through musical self-regulation in pulse, rhythm and pitch is moving from an 'up-regulation' attitude to a communion attitude (Stern, 
Table 4

Musical transcription of episode 3 and its microanalytic description and evaluation

Ferdinando Michele Suvini, Fabio Apicella, Filippo Muratori

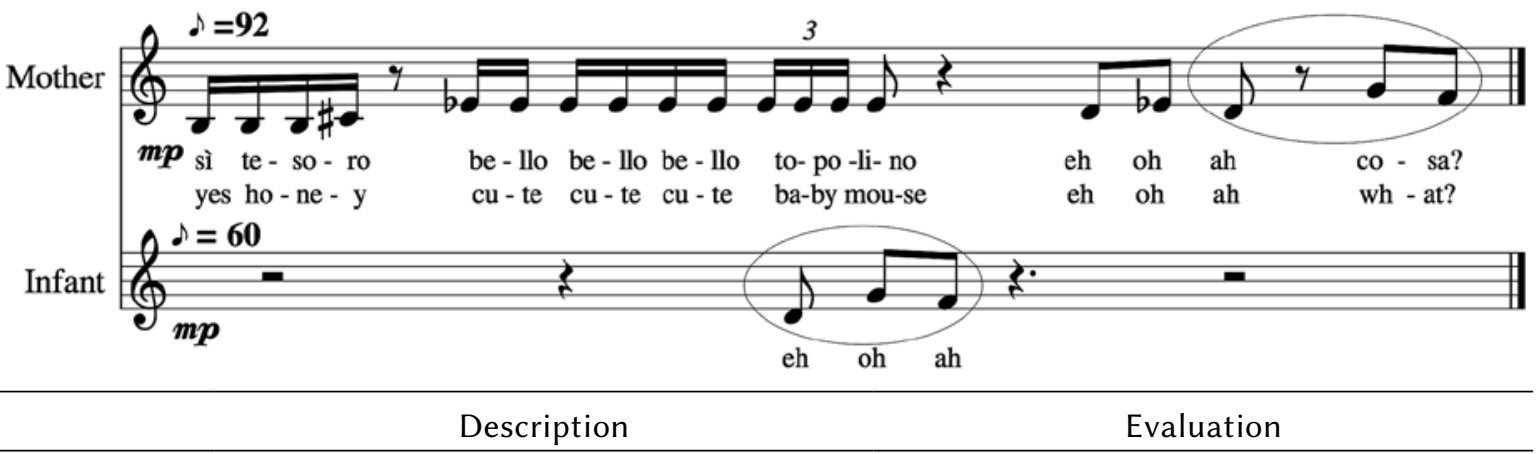

\begin{tabular}{|c|c|c|}
\hline $\begin{array}{l}\text { Narrative } \\
\& \text { Form }\end{array}$ & $\begin{array}{l}\text { Musical material is mostly } \\
\text { proposed by the mother. }\end{array}$ & The mother relates more to the infant. \\
\hline Pulse & $\begin{array}{c}\text { The mother's metronome beat is } 92, \\
\text { the infant's is } 60 .\end{array}$ & $\begin{array}{l}\text { The mother's pulsation is } \\
\text { faster than the infant's. }\end{array}$ \\
\hline Rhythm & $\begin{array}{c}\text { The rhythm is stable: there is regularity, } \\
\text { phrasing and repetition. }\end{array}$ & $\begin{array}{l}\text { The mother's proposal is predictable } \\
\text { and allows for reciprocity. }\end{array}$ \\
\hline $\begin{array}{l}\text { Repetition } \\
\text { \& Imitation }\end{array}$ & $\begin{array}{l}\text { The musical material is based } \\
\text { on repetition and imitation. }\end{array}$ & $\begin{array}{l}\text { The episode of imitation is } \\
\text { a clear example of listening } \\
\text { (the ascending perfect fourth). }\end{array}$ \\
\hline Intensity & $\begin{array}{l}\text { The mother's intensity }(m p) \\
\text { is almost the same } \\
\text { as the infant's }(m p)\end{array}$ & $\begin{array}{l}\text { The mother is closer to the infant } \\
\text { at the same level of intensity as the infant. }\end{array}$ \\
\hline Timbre & $\begin{array}{l}\text { The mother's timbre is more similar to the } \\
\text { infant's timbre. }\end{array}$ & $\begin{array}{l}\text { Timbre represents identity. } \\
\text { Mother and infant are closer than before. }\end{array}$ \\
\hline $\begin{array}{l}\text { Pitch } \\
\& \text { Melody }\end{array}$ & $\begin{array}{l}\text { The mother is in the same range as the } \\
\text { infant. }\end{array}$ & $\begin{array}{l}\text { Pitch and melody show } \\
\text { a closer relationship. }\end{array}$ \\
\hline $\begin{array}{l}\text { Pause } \\
\& \text { Silence }\end{array}$ & $\begin{array}{l}\text { There is a short pause } \\
\text { between the phrases. }\end{array}$ & $\begin{array}{l}\text { There is space for the infant } \\
\text { in the inner world of the mother. }\end{array}$ \\
\hline Semantic & \multicolumn{2}{|c|}{$\begin{array}{l}\text { The mother's language relates to the present moment (Stern, 2004), } \\
\text { in an interpersonal communion way. }\end{array}$} \\
\hline
\end{tabular}

1985), with less intention to alter the infant's experience and more mindedness towards sharing emotion and affect with him.

In the third episode, the mother proposes a regular phrase and imitates the child's vocalizations. In the phrase there is reciprocity in pitch, intensity and timbre. The episode of imitation involves rhythm, intensity, pitch and timbre. Through imitation, the mother's musicality includes the infant's musicality in parameters such as rhythm, pitch, intensity and form. There is a dynamic equilibrium between structure and variation, and also a temporal frame of expectation that could facilitate the infant perception of temporal structure (Fernald, 1985; Gratier, 2009). This different musical scenario can generate an inner sense of time, an interpersonal communion between the mother and the infant.

To summarize, the first episode describes, from a musical point of view, a clear example of a par- ent's up-regulation when confronted with a socially withdrawn infant; this first episode seems to be dominated by the anxiety of the mother, who attempts to stimulate the autistic infant. The second episode contains evidence of qualitative musical changes in the parent-infant interaction. The third episode is a clear example of a 'good enough' interaction where the mother's participation in the infant's experience, and at the same time the lowering of her intention to change, can be described through modifications in reciprocal rhythm, pitch and other musical aspects of interaction. This third episode could be an example of interpersonal communion between the mother and the infant.

Thus, musical microanalysis allowed us to describe the process of early parent-infant interaction and how it is shaped, disrupted and also repaired in the case of an ASD during the first months of life. Second, it was able to highlight features and details 
that are not recorded by other kinds of analysis just based on the transcription in a musical score (Wosch \& Wigram, 2007). Third, it represents a possible way to explore the potential shift in autism research, by focusing on dynamic parent-infant interactions instead of single behaviors of the child and/or of the parent (Schore, 2014).

From our microanalysis autism emerges as a failure in the creation of the early dual space between the infant and the mother. The lack of this original space can impair the integration of motives to move in purposeful ways with self and other awareness. Thanks to the fundamental dimensions of time, form and intensity, as basic events through which the interpersonal coordination occurs, our musical microanalysis provides information on the quality of the relationship and has proved to be able to catch their changes in a small temporal space. Musical modifications in the second and in the third episodes have created the condition for the emergence of parentese. These different musical interactions become evident when: 1) the mother produces more regular melodic phrases; 2) intensity, timbre and pitch are all more similar to those of the infant; 3) during imitation the mother reaches the same interval as the child (ascending perfect fourth); 4) the mother uses the third person instead of the second. All these characteristics suggest that the mother is approaching parentese, which in turn creates a closer link between the mother and her three-month-old infant. These modifications toward parentese suggest that the child's presence becomes capable of modifying the parent's quality of interaction; in a natural and unconscious way parents tend to synchronize their own vocal production with the affects and behavior of the infant, thus co-creating a new musical space within the dyad. The child, just with his/her presence, is in an interactive contact with the mother who is conversing with him; at this point, the mother's music cannot simply be considered as an 'acoustic signal', more or less interesting; instead, it is a product of the presence of a human being who meets another, and is therefore connected through intentions, emotions, and affects. This is what we have called interpersonal communion compared to interpersonal communication. This does not mean that parents should not assume an active position when engaging a child in the interaction; however, they have to arrive at a less directive style which supports the child's actions and contingency (Wimpory, Hobson, \& Nash, 2006), as happens in the third episode.

Schumacher has defined this particular type of behavior as 'active inactivity', as it relates to enfolding, containing, gathering, and incorporating in a music scenario the expressive elements of the infant (Schumacher \& Calvet, 2007). From the music therapy perspective, this author underlines that this attitude encourages the emergence of a 'subjective self' and the determination of 'self-awareness'. We hypothesize that, in clinical improvisational music therapy, as in early interaction, it is possible to get affectively closer to the autistic person while still maintaining a considerable physical distance (Holck \& Geretsegger, 2016). However, we have to consider that the level of "optimal affective distance" can be different every time and with each patient. Knowing how to identify and recognize this distance is one of the challenges for the expert music therapist who wants to help and support infant musicality and, when parents are actively involved as in parent-mediated treatment for autism, parent-infant musicality.

Finally, we think that this single case deep analysis needs to be empirically sustained by future research on a larger sample and eventually also with children with other kinds of disorders different from ASD. Nevertheless, it paves the way for this type of research and, most importantly, has showed its feasibility.

\section{References}

American Psychiatric Association (APA). (2013). Diagnostic and Statistical Manual of Mental Disorders (DSM-5). $5^{\text {th }}$ ed. Arlington, VA: American Psychiatric Publishing.

Ansdell, G., Davidson, J., Magee, W. L., Meehan, J., \& Procter, S. (2011). From "this $\mathrm{F}^{* * *}$ life" to "that's better" in four minutes: an interdisciplinary study of music therapy's "present moment" and their potential for affect modulation. Nordic Journal of Music Therapy Publisher Routledge, 19, 3-28.

Apicella, F., Chericoni, N., Costanzo, V., Baldini, S., Billeci, L., Cohen, D., \& Muratori, F. (2013). Reciprocity in interaction: a window on the first year of life in autism. Autism Research and Treatment, 705895. doi: 10.1155/2013/705895.

Bruscia, K. (1987). Improvisational models of music therapy. Springfield, IL: Charles C. Thomas Publisher.

Burnham, D., Kitamura, C., \& Vollmer-Conna, U. (2002). What's new, pussycat? On talking to babies and animals. Science, 296, 1435.

Cohen, D., Cassel, R. S., Saint-Georges, C. C., Mahdhaoui, A., Laznik., M-C., Apicella, F., Muratori, P., Maestro, S., Muratori, F., \& Chetouani, M. (2013). Do parentese prosody and fathers' involvement in interacting facilitate social interaction in infants who later develop autism? PLoS One, 8, e61402.

Danon-Boileau, L. (2007). Early signs related to posture and communication: the child's attitude, and the mother's reaction. In S. Acquarone (ed.), Signs of autism in infants: recognition and treatment (pp. 63-79). London: Karnac Books.

De Backer, J. (2004). The transition from sensorial play to musical form. Dissertation for PHD Thesis In-
Microanalysis of early parent-infant interactions in autism 
stitute of Music and Music Therapy, Aalborg University.

Doussard-Roosevelt, J. A., Joe C. M., Bazhenova, O. V., \& Porges, S. W. (2003). Mother-child interaction in autistic and nonautisitic children: characteristics of maternal approach behaviors and child social responses. Developmental Psychopathology, 15, 277-295.

Durkin, K., Rutter, D. R., \& Tucker, H. (1982). Social interaction and language acquisition: Motherese

Ferdinando Michele Suvini, Fabio Apicella, Filippo Muratori

\section{help you. First Language, 3, 107-120.}

Ferguson, C. A. (1964). Baby talk in six languages. American Anthropologist, 66, 103-114.
Fernald, A. (1985). 4-month-old infants prefer to listen to motherese. Infant Behavior \& Development, 8, 181-195.

Fisher, C., \& Tokura, H. (1995). The given-new contract in speech to infants. Journal of Memory and Language, 34, 287-310.

Garcia-Perez, R. M., Lee, A., \& Hobson, R. P. (2007). On intersubjective engagement in autism: a controlled study of nonverbal aspects of conversation. Journal of Autism Developmental Disorders, 37, 1310-1322.

Geretsegger, M., Holck, U., Carpente, J. A., Elefant, C., Kim, J., \& Gold, C. (2015). Common characteristics of improvisational approaches in music therapy for children with autism spectrum disorder: developing treatment guidelines. Journal of Music Therapy, 52, 258-281.

Giusti, M., \& Suvini, F. (2014). Music therapy and ASD: Psychodynamic Music Therapy and Inter-subjectivity. In G. Corrado, G. La Malfa, \& A. Stefano (eds.), Qualità della Vita tra mente e Corpo [Quality of Life between Mind and Body] (pp. 118-138). Edizioni Maddali e Bruni Florence.

Gratier, M. (2009). Grounding in musical interaction: Evidence from jazz performance. Musicae Scientiae, $12,71-110$.

Grieser, D. L., \& Kuhl, P. K. (1988). Maternal speech to infants in a tonal language: Support for universal prosodic features in motherese. Developmental Psychology, 24, 14-20.

Holck, U. (2004). Interaction Themes in music therapy: definition and delimitation. Nordic Journal of Music Therapy, 13, 3-19.

Holck, U., \& Geretsegger, M. (2016). Musical and emotional attunement: unique and essential in music therapy with children on the autism spectrum. Nordic Journal of Music Therapy, 25, Suppl, 34-35.

Maestro, S., Muratori, F., Cavallaro, M. C., Pei, F., Stern, D., Golse, B., \& Palacio-Espasa, F. (2002). Attentional skills during the first 6 months of age in autism spectrum disorder. Journal of the American Academy of Child and Adolescent Psychiatry, 41, 1239-1245.
Maestro, S., Muratori, F., Cesari, A., Cavallaro, M. C., Paziente, A., Pecini, C., Grassi, C., Manfredi, A., \& Sommario, C. (2004). Course of autism signs in the first year of life. Psychopatology, 38, 26-31.

Malloch, S. (1999). Mothers and infants and communicative musicality. Musicae Scientiae (Special Issue), 29-57.

Muratori, F., Apicella, F., Muratori, P., \& Maestro, S. (2011), Intersubjective disruptions and caregiver infant interaction in early autistic disorder. $R e$ search in Autism Spectrum Disorders, 5, 408-417.

Muratori, F., \& Maestro, S. (2007). Autism as a downstream effect of primary difficulties in inter-subjectivity interacting with abnormal development of brain connectivity. International Journal for Dialogical Science, 2, 93-118.

O’Neill, C. T., Trainor, L. J., \& Trehub, S. E. (2001). Infants' responsiveness to fathers' singing. Music Perception, 18, 409-425.

Oono, I. P., Honey, E. G., \& McConachie, H. (2013). Parent-mediated early intervention for young children with autism spectrum disorders (ASD). Cochrane Database of Systematic Reviews, 4, CD009774.

Saint-Georges, C., Cassel, R. S., Cohen, D., Chetouani, M., Laznik., M.-C., Maestro, S., \& Muratori, F. (2010). What studies of family home movies can teach us about autistic infants: a literature review. Research in Autism Spectrum Disorders, 4, 355-366. Saint-Georges, C., Chetouani, M., Cassel, R. S., Apicella, F. C., Mahdhaoui, A., Muratori, F., Laznik., M-C., \& Cohen, D. (2013). Motherese in interaction: at the cross-road of emotion and cognition? A systematic review. PLoS One, 8, e78103.

Saint-Georges, C., Mahdhaoui, A., Chetouani, M., Cassel, R. S., Laznik., M.-C., Apicella, F., Muratori, P., Maestro, S., Muratori, F., \& Cohen, D. (2011). Do parents recognize autistic deviant behavior long before diagnosis? Taking into account interaction using computational methods. PLoS One, 6, e22393.

Schore, A. N. (2014). Early interpersonal neurobiological assessment of attachment and autistic spectrum disorders. Frontiers Psychology, 5, 1049.

Schumacher, K., \& Calvet, C. (2007). Music therapy with children based on developmental psychology, using the example of "synchronization" as a relevant moment. In U. Stiff \& R. Tüpker (eds.), Kindermusiktherapie - richtungen und methoden [Music therapy for children - directions and methods] (pp. 27-61). Göttingen: Vandenhoek \& Ruprecht.

Soderstrom, M., Blossom, M., Foygel, R., \& Morgan, J. L. (2008). Acoustical cues and grammatical units in speech to two preverbal infants. Journal of Child Language, 35, 869-902.

Stern, D. (1985). The interpersonal world of the infant: a view from psychoanalysis and developmental psychology. $1^{\text {st }}$ ed. New York: Basic Books. 
Stern, D. (2004). The present moment in psychotherapy and everyday life. New York: W. W. Norton \& Company.

Stern, D. (2010a). The issue of vitality. Nordic Journal of Music Therapy, 19, 88-102.

Stern, D. (2010b). Forms of vitality. Exploring dynamic experience in psychology and the arts. Oxford: Oxford University Press.

Suvini, F. (2015). Microanalisi e musicoterapia. Un possibile dialogo tra musica e parole [Looking for a dialogue between music and words]. In P.L Postacchini (ed.), Musicalità e Musicoterapia [Musicality and musictherapy]. Edizioni Carocci Roma.

Suvini, F., \& Muratori, F. (2016). Musicoterapia e autismo. Pratica clinica e Ricerca [Musictherapy and autism. Clinical treatment and research]. Editore Morlacchi, Perugia.

Trehub, S. E., \& Nakata, T. (2002). Emotion and music in infancy. Musicae Scientiae (Special Issue), 37-61.

Trevarthen, C., \& Aitken, K. J. (2001). Infant inter-subjectivity: Research, theory and clinical applications. Journal of Child Psychology and Psychiatry, 1, 3-48.

Trevarthen, C., \& Daniel, S. (2005). Disorganized rhythm and synchrony: early signs of autism and Rett syndrome. Brain and Development, 27, S25-S34.

Wan, M. W., Green, J., Elsabbagh, M., Johnson, M., Charman, T., \& Plummer, F. (2012). Parent-infant interaction in infant siblings at risk of autism. $R e$ search in Developmental Disabilities, 33, 924-932.

Wigram, T., \& Elefant, C. (2009). Therapeutic dialogues in music: Nurturing musicality of communication in children with autistic spectrum disorder and Rett syndrome. In S. Malloch \& C. Trevarthen (eds.), Communicative Musicality (pp. 423-446). Oxford: Oxford University Press.

Wigram, T., \& Gold, C. (2006). Music therapy in the assessment and treatment of autistic spectrum disorder: Clinical application and research evidence. Child: Care, Health and Development, 32, 535-542.

Wimpory, D. C., Hobson, R. P., \& Nash, S. (2006). What facilitates social engagement in preschool children with autism? Journal of Autism and Developmental Disorders, 37, 564-573.

World Health Organization (WHO). (1992). International Statistical Classification of Diseases and Related Health Problems. $10^{\text {th }}$ ed. Geneva: World Health Organization.

World Health Organization (WHO). (2012). International Classification of Diseases (ICD-11).

Wosch, T., \& Wigram, T. (2007). Microanalysis in music therapy. Philadelphia, USA: Jessica Kingsley Publishers. 